\title{
Contributions of nursing theories in the practice of the mental health promotion
}

Contributos das teorias de enfermagem na prática da promoção de saúde mental Contribuciones de las teorías de la enfermería en la práctica de la promoción de la salud mental Marina Nolli Bittencourt*(D); Maria Isabel Dias Marques**(D); Tereza Maria Mendes Diniz de Andrade Barroso***(D)

\begin{abstract}
Background: Mental health promotion is an important phenomenon for nursing sciences, which requires a perspective from nursing theories. Although the evidence points to the effectiveness of the interventions in this domain, it is little based on nursing theories.

Objective: To explore different theoretical contributions of nursing, taking as reference the phenomenon of mental health promotion.

Main topics under analysis: Mental health promotion, the philosophical perspective of post-modernism, the theory of interpersonal relations, the health promotion model, the transitions theory, and the adaptation model and their contributions to mental health promotion.

Conclusion: Some theoretical contributions to mental health promotion should be highlighted, such as the importance of building interpersonal relations with the patients (Peplau) and identifying the person as a biopsychosocial being (Pender) who undergoes transitions (Meleis) and requires support to adjust and adopt healthier behaviors (Roy).
\end{abstract}

Keywords: health promotion; mental health; nursing theory

\section{Resumo}

Enquadramento: A promoção da saúde mental constitui um fenómeno importante para as ciências da enfermagem, o que requer um olhar à luz das teorias de enfermagem, já que as evidências, apesar de indicarem eficácia das intervenções nesse domínio, pouco se fundamentam nas teorias de enfermagem.

Objetivo: Explorar diferentes contributos teóricos de enfermagem, tendo como referência o fenómeno da promoção da saúde mental.

Principais tópicos em análise: Promoção da saúde mental, a perspetiva filosófica do pós-modernismo, a teoria das relaçôes interpessoais, a teoria modelo de promoçáo da saúde, a teoria das transiçóes e a teoria modelo de adaptação e os seus contributos na promoção da saúde mental. Conclusáo: Salientam-se alguns contributos teóricos para a promoção da saúde mental, como a importância de se construírem relaçóes interpessoais com o sujeito a ser cuidado, conforme Peplau; identificar o sujeito como um ser biopsicossocial, como proposto por Pender; que passa por transiçóes, conforme Meleis; e que, para tanto, precisa de apoio para se adaptar e adotar comportamentos mais saudáveis, de acordo com Roy.

Palavras-chave: promoção da saúde; saúde mental; teoria de enfermagem

*Ph.D., RN, Adjunct Professor, Federal University of Amapá, 68903-419, Macapá, Brazil [marinanolli@ hotmail.com].O https://orcid.org/0000-0002-1660-3418. Contribution to the article: literature search, synthesis and organization of contents, conceptual analysis and reflection, documentary analysis, article writing, and revision of the final version. **Ph.D., Coordinating Professor, Nursing School of Coimbra, 3046-851 Coimbra, Portugal [imarques@esenf.pt].Dhttps://orcid.org/0000-0002-8720-2419 Contribution to the article: synthesis and organization of contents, conceptual analvsis and reflection, documencle: synthesis and organization of contents, conceptual anal
tary analysis, article writing, and revision of the final version.

***:Ph.D.,Adjunct Professor, Nursing School of Coimbra, 3046-851 Coimbra, Portugal [tbarroso@ esenfc.pt].O https://orcid.org/0000-0002-9411-6113. Contribution to the article: conceptual analysis and reflection, documentary analysis, article witing, and revision of the final version. Address for correspondence: Rua Comercial, $\mathrm{n}^{0} 18$ - Bairro da Liberdade, 3020-112, Coimbra, Portugal.

\section{Resumen}

Marco contextual: La promoción de la salud mental constituye un fenómeno importante para las ciencias de la enfermería. Esto requiere una mirada a las teorías de la enfermería, ya que las pruebas, a pesar de indicar la eficacia de las intervenciones en ese ámbito, se fundamentan poco en las teorías de la enfermería.

Objetivo: Explorar diferentes contribuciones teóricas de la enfermería, tomando como referencia el fenómeno de la promoción de la salud mental.

Principales temas en análisis: Promoción de la salud mental, la perspectiva filosófica del posmodernismo, la teoría de las relaciones interpersonales, la teoría modelo de promoción de la salud, la teoría de las transiciones y la teoría modelo de adaptación y sus contribuciones en la promoción de la salud mental.

Conclusión: Se subrayan algunas contribuciones teóricas para la promoción de la salud mental, como la importancia de construir relaciones interpersonales con el sujeto que debe ser cuidado, de acuerdo con Peplau; identificar al sujeto como un ser biopsicosocial, como propone Pender; que pasa por transiciones, según Meleis; y que, para ello, necesita apoyo para adaptarse y adoptar comportamientos más saludables, de acuerdo con Roy.

Palabras clave: promoción de la salud; salud mental; teoría de enfermería 


\section{Introduction}

According to the Global Burden of Disease Study, mental health disorders are among the 10 leading causes of disability. At the end of childhood (6-15 years), some of the leading causes of disability are conduct, autism spectrum, and anxiety disorders; in adolescence, depression, anxiety, and schizophrenia (15-39 years); and in adulthood, depression (Global Burden of Disease Study, 2016).

However, many of these disorders could be avoided if health professionals analyzed more closely the meaning of mental health and the factors influencing its imbalance. In this way, they could propose more effective strategies taking into account the specificities of each region.

According to the World Health Organization (WHO), mental health is a state of well-being in which every individual realizes her or his own skills, can cope with the stresses of everyday life, can work productively and fruitfully, and is able to contribute to the community where she or he lives (WHO, 2014).

Therefore, to promote mental health, health professionals need to go beyond the health prevention strategies and use health, well-being, and environmental balance promotion strategies which, since the mid-19th century with Florence Nightingale's environmental theory, have been led by nurses. The idea of nurses as leaders in health promotion strategies has also been strengthened by WHO, which puts the emphasis on strengthening nursing to improve the health and well-being of the world population through physical and mental health and well-being promotion strategies coordinated by nurses who have acquired skills during their training to implement these strategies (WHO, 2016a).

For nurses to become these leaders, it is essential to recognize that the foundations of health promotion have been based on individual behavior, which includes a wide range of social and environmental interventions, and should involve three key elements: the implementation of public policies for improving health; healthy cities that play a key role in promoting good health; and the improvement of health literacy (WHO, 2016b).

In this way, mental health promotion can be considered an integral part of health promotion practices, since the WHO defines it as actions that involve creating environments which provide the necessary conditions for the full development of mental health and the adoption of a healthy lifestyle (WHO, 2016c). Mental health promotion can be seen as one of the phenomena involving the nursing sciences which, despite not having an established theory, is a phenomenon that covers several approaches. These approaches are intertwined and, together, are directed towards the development of healthy environments, relationships, feelings, and attitudes. Thus, considering that mental health promotion strategies are included in the health promotion approach, mental health promotion can be considered as a nursing phenomenon which, despite not having an established theory, is influenced by theories proposed by nurses.

It should be noted that nurses have been conducting studies with the purpose of promoting mental health in schools and other settings (Markle-Reid et al., 2014; McAllister, Knight, \& Withyman, 2017). However, although these studies are based on evidence that clearly point to the effectiveness of promotion strategies, nursing theories are rarely put forward as a basis for these nurseled mental health promotion strategies. In this way, with regard to the positive view proposed for the mental health promotion phenomenon (WHO, 2016c), some nursing theories should be highlighted given that they can contribute to the development of nursing practices related to this phenomenon: Peplau's theory of interpersonal relations (1952), who was the first female nurse theorist of psychiatric nursing and points to the need for interpersonal relations so that patients can, together with the nurse, reach their personal growth and development (Peplau, 1990); Pender's health promotion model (2001), according to which nursing is essential in changing behaviors to achieve a healthier lifestyle (Pender, Murdaugh, \& Parsons, 2011); Meleis' transitions theory (1997), according to which individuals undergo transitions throughout their lifecycle and nurses must be able to identify those moments and make them healthier (Meleis, Sawyer, 
Im, Hilfinger Messias, \& Schumacher, 2000); and, finally, Roy's adaptation model, according to which individuals are able to adapt themselves and nurses are responsible for facilitating the access to healthy adaptive responses (Roy \& Andrews, 2001).

In view of these theories, and considering the philosophical perspective of the post-modernism paradigm which corresponds to the positive view proposed for this phenomenon (WHO, 2016c), this study aims to explore the different theoretical contributions of nursing, taking as a reference the mental health promotion phenomenon.

\section{Philosophical perspective on the mental health promotion phenomenon}

The mental health promotion phenomenon will be explored in light of the philosophical perspective of post-modernism. According to post-modernism, people are an effect or result of social and historical processes, which translates into a very positive approach to philosophy, since it seeks to create space for diversity and inclusiveness, thus influencing the development of knowledge in nursing sciences in the late $20^{\text {th }}$ century (Nicholls, 2012).

This new perspective of nursing includes a recognition of changes and the plasticity of events, regressing to the context more than to the authority of the abstract voice of theory. This leads us to recognize that knowledge is built as a human effort which, by considering pluralism and ambiguity, opens room for new possibilities and questioning about the truth of the concepts, including the concept that knowledge is not fixed, but rather involves fallibility, self-revision, and self-reflection (Watson, 1995).

In this way, the mental health promotion phenomenon will be studied through the lenses of post-modernism, since the definition of mental health promotion, based on a positive view (WHO, 2016c), includes the development of healthy environments, relationships, feelings, and positive attitudes, as well as the promotion of quality of life by looking at the human condition as a whole. This pluralism moves away from the western philosophical perspective, according to which mental health is directed toward mental disorders and deficits.

\section{Development}

\section{Nursing theories in nurses' practices}

Throughout the evolution of nursing sciences, the scientific nature of nursing was sometimes questioned, which led to the development of several theories as a way of supporting nursing practice (Nóbrega \& Santos, 1996).

However, nowadays, there are only a few nursing studies describing practices based on actual theories of the nursing discipline (Karnick, 2014). Theories themselves have been disappearing not only from research but also from training and practice, which may be related to the fact that there is a misunderstanding about the real focus of nursing, its philosophical foundation, and the global political pressure to take away the professional nature of nursing (Hoeck \& Delmar, 2017; Thorne \& Sawatzky, 2014). That can transform nursing from a key profession in caring for patients and their families into a set of tasks, rules, and decisions proposed by others (Karnick, 2014).

In this way, nursing theories should not be undervalued, but rather strengthened, both in nurses' training and in daily practice with the purpose of promoting and improving the health status of people and groups and not only increasing the indicators and productivity, because nursing sciences must be based on theoretical assumptions (Jensen \& Andersen, 2005).

So, exploring these different theoretical contributions of nursing, taking as reference the mental health promotion phenomenon, will allow us to reflect on a nurse-led care strategy (WHO, 2016a) which is still underexplored in nursing sciences.

\section{Theory of interpersonal relations, health promotion model, transitions theory, and adaptation model in mental health promo- tion practices}

In recent years, several publications by the WHO and other groups, such as the All-Party Parliamentary Group on Global Health, have set the agenda for universal health coverage through physical and mental health and well-being promotion strategies, equal access to health services, and the strengthening of nursing, since nurses are the largest group 
of health professionals and play a key role in the implementation of these strategies worldwide (WHO, 2016a; All-Party Parliamentary Group on Global Health, 2016).

In this way, nurses should have access to high-quality education and information and use theories and evidence to propose mental health promotion strategies. These theories allow for a reflection on the aspects to be considered when proposing strategies for the adoption of healthier behaviors by individuals, their families, and the communities where they live.

Some authors based their theories on the contributions of Psychology. For example, Hildegard Peplau used the theories of Sullivan and Freud as the theoretical basis for her model, being the first nurse to give theoretical contributions within the scope of psychiatric nursing.

According to Peplau's theory, interpersonal relations are essential for patients and nurses to grow and develop together, so it is a dynamic process which should take place during the nursing care process. Other important agents in this process are the family, the culture, the society, and the place where these changes occur (Peplau, 1990).

For this interpersonal relationship to exist, Peplau proposes a four-phase process: orientation, identification, exploitation, and resolution. The first phase - orientation - is the moment of the first interaction in which the nurse will identify the patients' needs and information about the problem they are experiencing. After obtaining this information, the nurse and the other team members will be able to guide the patient about the problem, taking into account feelings such as anxiety. In the second phase - identification, the nurse will help the patient to identify the main strategies for meeting their needs. The third phase - exploitation - is the moment in which the nurse-patient relationship should be strengthened and exploited to the fullest extent possible to achieve the best outcomes, such as becoming more independent and making full use of the services. At this moment, the nurse continues to assist the patient in satisfying their needs and setting new life goals. The fourth and last phase - resolution - is the moment in which patients gradual- ly drift way and break bonds with those who helped them and feel empowered to solve their problems on their own. This phase is reached after the remaining phases have been completed successfully (Peplau, 1990).

It should be noted that, although Peplau's theory does not address the concept of health promotion, the author proposes the gradual development of an interpersonal relationship between nurses and patients, in which it will be possible for nurses to help patients to identify specific needs to reach their independence and autonomy, and provide them with tools to improve their physical and mental health. Nola Pender's health promotion model (Pender et al., 2011) goes even beyond and provides tools for understanding the biopsychosocial issues associated with the individuals' decision to adopt a healthy behavior. This model is also based on some theories of Psychology, such as Albert Bandura's social cognitive theory. The key concepts in Pender's model are the person, who is a biopsychosocial organism that is partially shaped by the environment and seeks environments where their characteristics are easily expressed; the environment, which is a social, cultural, and physical context in which life unfolds and that can be shaped to facilitate healthier behaviors; nursing, which collaborates with the community, individuals, and families to create an environment that promotes health and well-being; health, as behaviors that involve self-care, satisfying relationships, and attitudes that promote a healthy and structured environment; and illness, either acute or chronic, which can hinder or facilitate the adoption of healthy attitudes (Pender, 2012). Therefore, Pender's health promotion model joins Peplau's theory in the mental health promotion phenomenon because it helps the nurse to understand the factors underlying the biopsychosocial process which influence the individual's adoption of a healthy lifestyle so that nurses can propose the necessary tools for changing this behavior.

Meleis' transitions theory also complements the discussion of these two theories because it argues that individuals must incorporate new issues in their lives to adopt a new lifestyle. This process requires acquiring new knowledge, as well as changing behaviors and how 
one defines oneself, that is, it puts forward important tools for healthier transitions in various aspects of life (Meleis et al., 2000). Thus, there are different types of transitions because this process is very complex and unique. They may be related to a change in the developmental phase, a life situation, a health/illness process, or issues involving the social, political or economic environment of the individuals. Moreover, there are also different patterns, that is, transitions can happen in a single moment, in a simultaneous or sequential manner, and they may be related or unrelated. Finally, these transitions have properties, including critical points and events, change and difference, time span, awareness, and engagement (Meleis et al., 2000).

For nurses to be able to understand what patients go through during the transition processes, they must first identify their personal characteristics and the characteristics of the society and community where they live, as these factors can facilitate or hinder the transition process which involves rebuilding their identity, changing behaviors, and applying new skills in their life (Meleis et al., 2000).

Finally, it is essential to assess the indicators showing how the individual responds to the transition process in order to identify if this process promotes their health and well-being or leads to risks and situations of vulnerability (Meleis et al., 2000). In this way, these indicators may relate to how the individual who experiences this process interacts with the people around her/him such as family and health professionals; how the individual feels attached to them; how the individual is situated in time; and the coping strategies used in this process (Meleis et al., 2000).

To assess the outcomes of this process, it is important to assess how individuals master the new skills and rebuild their identity, achieving a healthy transition process. Moreover, to ensure that these outcomes are achieved, the nurse should be present throughout the process and provide knowledge to the individuals experiencing it and those around them, promoting health and well-being (Meleis et al., 2000).

In Meleis' transitions theory, nurses have tools to better understand the factors involved in a life transition process and promote health.
For a successful educational intervention, they should be aware of the characteristics of this process, the subject experiencing it, and the place where she/he lives.

In Roy's adaptation model, it is possible to reflect on the adaptive modes of the individual as a unique person or as a group, and how nurses can help them achieve a healthier adaptation. Roy identifies four adaptive modes. The first is called the physiologic-physical mode, which includes the basic needs such as nutrition, oxygenation, activity and rest, elimination, and protection. Another adaptive mode is self-concept, which is the need to identify oneself as a unique being, with one's own identity, including the physical self (body sensation and body image) and the personal self (self-consistency, self-ideal, and moral-ethical-spiritual self; Roy \& Andrews, 2001). The role function is an adaptive mode related to how the individual integrates a social role and the need to know one's role in society so that one can act in a specific manner. The last adaptive mode - interdependence - is related to the nurse's role in giving and receiving affection, respect, love, and motivation, which can also involve significant others, support systems, the infrastructure, and the resources. It can be influenced by both external factors, such as culture and politics, and internal factors, such as principles and visions. According to Roy's theory (Roy \& Andrews, 2001), the nurse plays a key role in health promotion by promoting adaptations, thus nursing would be the science and practice capable of improving the adaptation skills and seeking transformations in the environment in which the individual lives, the individual her/himself, and her/his group. Her theory creates a positive encounter with the above-mentioned theories and reinforces the meaning of mental health promotion because, by knowing the individual's adaptive modes, we are able to propose personal strategies for solving and coping with problems and promoting well-being and self-esteem.

After analyzing the contributions of the theory of interpersonal relations, the health promotion model, the transitions theory, and the adaptation model based on the perspective of the philosophical movement of post-modernism, and taking as reference WHO'S defi- 
nition of mental health promotion (2016c), Figure 1 was designed with the purpose of showing these theories' contributions, which converge with WHO's definition.

By reflection on these theories, we observed that nurses should have a comprehensive approach towards the patient to promote mental health, taking into account that people are biopsychosocial beings, that is, they are shaped by the environment where they live, influenced by their family, society, and culture, and undergo life transitions such as their physical and psychosocial development. To achieve this, they need to adapt to these transitions and the environment where they live, as can be seen in the circle shown on the right in Figure 1.
Thus, with this comprehensive approach, the nurse is prepared to propose mental health promotion strategies, as shown in the above-mentioned theories. These strategies involve the promotion of well-being and health, the introduction of new knowledge and skills, the development of interpersonal relations between the nurse and the patient, the promotion of a healthy growth, development, and lifestyle, the promotion of a healthy environment, the recognition of the individual's autonomy, the role of public policies, the promotion of interdependence, and helping the individual to perceive him/herself as an agent who promotes her/his own health, among other activities shown on the left in Figure 1.

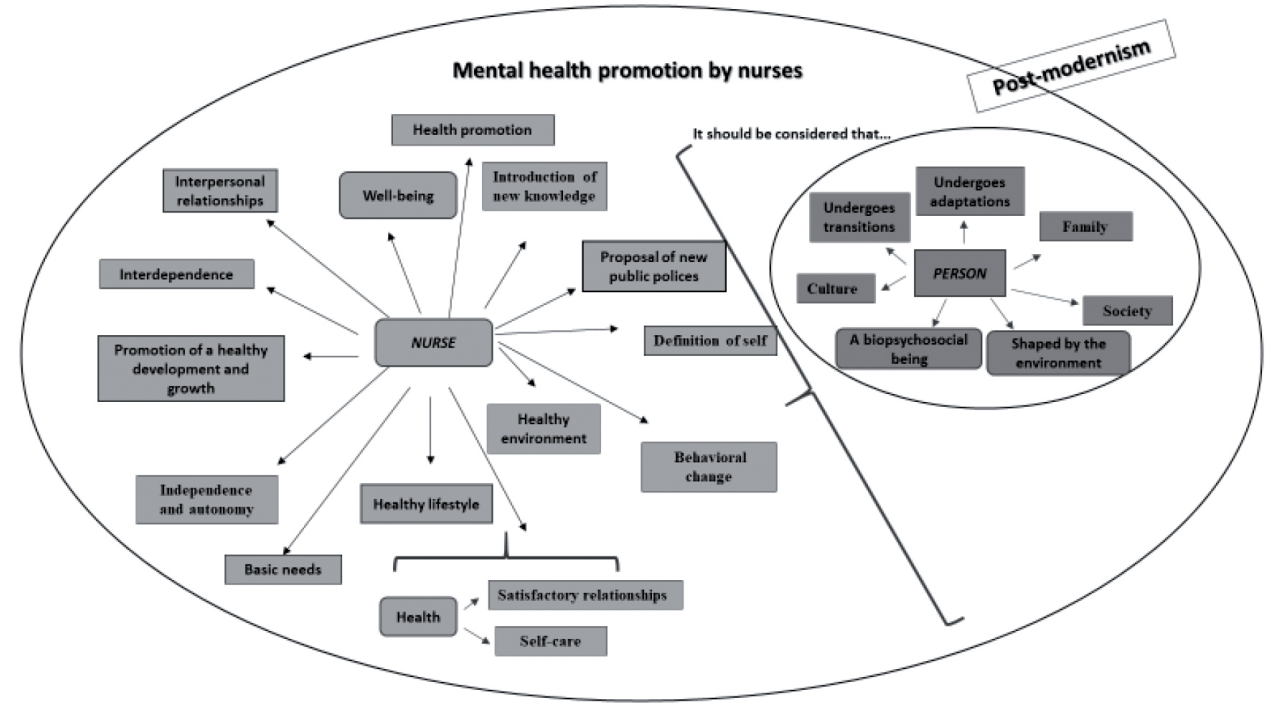

Figure 1. Mental health promotion in light of the philosophical movement of postmodernism and the theory of interpersonal relations, the health promotion model, the transitions theory, and the adaptation model.

Figure 1 was designed based on the theoretical contributions of the above-mentioned theories and shows the importance of considering the person as a whole to identify the nurse-led mental health promotion strategies proposed by these theories, which converge with WHO's definition of mental health promotion (2016c).

\section{Conclusion}

By exploring the different theoretical contributions of Peplau's theory of interpersonal relations, Pender's health promotion model, Meleis' transitions theory, and Roy's adaptation model, it was possible to realize that mental health promotion is a complex phe- 
nomenon which should be reflected upon using similarly complex theories.

Therefore, some contributions of the theories proposed for mental health promotion should be highlighted, such as the importance of building effective interpersonal relations between nurses and patients, as proposed by Peplau, looking at people as biopsychosocial beings, according to Pender, as well as understanding that the person undergoes transitions, according to Meleis, and needs support to adopt healthier behaviors, as proposed by Roy.

In this way, to strengthen nursing leadership in mental health promotion, it is essential to reinforce the theoretical contributions of nursing, which propose strategies on how to build healthy life projects, create environments that promote a culture of peace, the integration of communities, and a collective approach, and propose policies to strengthen nursing leadership in mental health promotion. If we do this, it will be possible to strengthen and change attitudes and lifestyles, based on the theoretical contributions of nursing, for a broad implementation of this process in the search for a positive, scientific nursing leadership.

\section{References}

All-Party Parliamentary Group on Global Health. (2016). Triple Impact: How developing nursing will improve health, promote gender equality and support economic growth. Retrieved from http://www.who. int/hrh/com-heeg/digital-APPG_triple-impact.pdf?ua $=1 \& u a=1$

Global Burden of Disease Study (2016). Disease and Injury Incidence and Prevalence Collaborators. Global, regional, and national incidence, prevalence and years lived with disability for 310 disears and injuries, 1990-2015: a systematic analysis for the Global Burden of Disease Study 2015. Lancet, 388, 1545602. doi:10.1016/50140-6736(16)31678-6.

Hoeck, B., \& Delmar, C. (2017). Theoretical development in the context of nursing: The hidden epistemology of nursing theory. Nursing Philosophy, 19(1), 1-10. doi: 10.1111/nup.12196

Jensen, U. J., \& Andersen, P. F. (2005). Sundhedsbegreber: Filosofiog praksis [Health concepts: Philosophy and practice] ( $2^{\text {nd }}$ ed.). Aarhus, Denmark: Philosophia.
Karnick, P. M. (2014). A case for nursing theory in practice. Nursing Science Quarterly, 27(2), 117. doi: 10.1177/0894318414522711

Markle-Reid, M., McAiney, C., Forbes, D., Thabane, L., Gibson, M., Browne, G., . . Busing, B. (2014). An interprofessional nurse-led mental health promotion intervention for older home care clients with depressive symptoms. BMC Geriatrics, 14(62), 1-23. doi: 10.1186/1471-2318-14-62

McAllister, M., Knight, B. A., \& Withyman, C. (2017). Merging contemporary learning theory with mental health promotion to produce an effective schoolsbased program. Nurse Education in Practice, 25, 7479. doi: 10.1016/j.nepr.2017.05.005

Meleis, A. I., Sawyer, L. M., Im, E. O., Hilfinger Messias, D. K., \& Schumacher, K. (2000). Experiencing transitions: An emerging middle range theory. Advances in Nursing Science, 23(1), 12-28. doi: 10.1097/00012272-200009000-00006

Nicholls, D. A. (2012). Postmodernism and physiotherapy research. Physical Therapy Reviews, 17(6), 360368. doi:10.1179/1743288X12Y.0000000045

Nóbrega, S. S., \& Santos, M. M. (1996). Teoria das relaçôes interpessoais em enfermagem de peplau: Análise e evolução. Revista Brasileira de Enfermagem, 49(1), 55-64. doi: 10.1590/S0034-71671996000100007

Pender, N. (2012). The Health Promotion Model: Manual online. Retrieved from http://deepblue.lib.umich.edu/bitstream/handle/2027.42/85350/HEALTH_PROMOTION_MANUAL_Rev_5-2011.pdf

Pender, N., Murdaugh, C., \& Parsons, M. A. (2011). Health promotion in nursing practice. Boston, MA: Pearson

Peplau, H. E. (1990). Relaciones interpersonales en enfermería: Un marco de referencia conceptual para la enfermería psicodinámica. Barcelona, Spain: Salvat Editores.

Roy, C., \& Andrews, H. A. (2001). The Roy adaptation model. Lisboa, Portugal: Instituto Piaget.

Thorne, S., \& Sawatzky, R. (2014). Particularizing the general: Sustaining theoretical integrity in the context of an evidence-based practice agenda. Advances in Nursing Science, 37(1), 5-18. doi: 10.1097/ ANS.0000000000000011

Watson, J. (1995). Postmodernism and knowledge development in nursing. Nursing Science Quarterly, 8(2), 60-64. doi: 10.1177/089431849500800207

World Health Organization. (2014). Mental health: A state of well-being. Retrieved from http://www.who. int/features/factfiles/mental_health/en/

World Health Organization. (2016a). Global strategic directions for strengthening nursing and midwifery 2016-2020. Retrieved from http://www.who.int/ 
hrh/nursing_midwifery/global-strategic-midwifery2016-2020.pdf

World Health Organization. (2016b). What is health promotion? Retrieved from http://www.who.int/ features/qa/health-promotion/en/

World Health Organization. (2016c). Mental health: Strenghtening our response. Retrieved from http:// www.who.int/mediacentre/factsheets/fs220/en/ 